\title{
Field emission of electrons from laser produced silicon tip arrays
}

\author{
A.A. Evtukh, E.B. Kaganovich, V.G. Litovchenko, Yu.M. Litvin, D.V. Fedin, E.G. Manoilov, \\ S.V. Svechnikov \\ Institute Semiconductor of Physics, National Academy of Sciences, Ukraine, \\ 45 Prospect Nauki, 03028, Kiev, Ukraine \\ Fax:(380-44)265-83-42,E-mail:Evt@book.semicond.kiev.ua.
}

\begin{abstract}
The new preparation method of silicon tips with nanocomposite structure, namely laser modification of silicon is developed. The laser direct-write process has been applied, one by one (single) laser pulses formed the single rather uniform conical tips. In this process a silicon substrate is locally heated above its melting point by a pulse YAG:Nd ${ }^{3+}$ laser and translated by X-Y $100 \mu \mathrm{m}$ resolution motor stages. Arrays with different tip distance, height and shape of tips can be produced by varying the condition of laser processing. The silicon tip arrays with distance between tips approximately $50 \mu \mathrm{m}$ and height $0-100 \mu \mathrm{m}$ with radius of the top about $1 \mathrm{~mm}$ can be produced. As a result of intensive laser pulse influence, the silicon surface is very developed with many nanometer size protrudes on it covered with the nanocomposite films $\left(n c-\mathrm{Si}_{-} \mathrm{SiO}_{\mathrm{x}}\right)$. Several samples were stain etched and porous silicon layers were formed on the surface.

The electron field emission from laser produced silicon based nanocomposite structures into vacuum have been studied in dependence on conditions of their forming. The measurement of emission current were performed in the vacuum system which could be pumped to a stable pressure of $10^{-6}$ Torr. The diode measurement cell was used with constant emitter-anode spacing equal $20 \mu \mathrm{m}$. The field emission was obtained from nanocomposite structures in the drive voltage range from 100 to $1500 \mathrm{~V}$ and in the current range from $5 \mathrm{nA}$ to above $20 \mu \mathrm{A}$. The field emission current depends on the condition of silicon nanocomposite structure preparation strongly. The emission parameters: turn-on voltage, field enhancement coefficient and effective emitting area have been determined. The resonant tunneling phenomenon have been discovered on some samples with nanocomposite structures. As a rule, two or one resonant peaks have been observed. The current-voltage curves have assymetry in current maximum region which is determined with peculiarities of electron transport through resonant tunneling structures. These structures consist of $\mathrm{Si}$ quantum size nanocrystals in porous/or non-porous silicon oxide matrix. Due to the quantum-size effect, there are some energy levels in quantum well region, which cause increased tunneling probability under definite electric fields.

The electron emission parameters combined with non-lithography process of manufacturing make investigated silicon nanocomposite tips an attractive alternative to others.
\end{abstract}

Keywords: silicon tip, field emission, nanocrystal, nanocomposite films.

Paper received 20.06.00, revised manuscript received 15.09.00, accepted for publication 12.12.12.

\section{Introduction}

The advantages of silicon emitters are their compatibility with silicon solid state IC technology allowing the deep miniaturization. In spite of the progress in this field there are some problems connected wit $1 \mathrm{~h}$ efficiency, stability and uniformity of the electron field emission. As a rule, Si tips are obtained by lithography process. It is difficult enough for Si tip arrays fabrication [1].
To stabilize the emission current from Si tips some film coatings can be used. Although electron field emission studies in the past have concentration an atomically clean emitter surfaces under ultra high vacuum (UHV) conditions, an atomically clean surface cannot be expected to be maintained in any practical devices. The $\mathrm{SiO}_{2}$ film inherently exists on the silicon surface in case of the non-ultrahigh vacuum. The reduction of the emission current density from silicon emitter covered with an oxide layer a few monolayers thick is occurred [2]. 


\section{A.A. Evtukh et al.: Field emission of electrons from laser produced silicon tip arrays}

To improve of the silicon emitter parameters, different covers such as diamond-like carbon films, Cs-enriched dielectric layers, porous silicon layers are widely investigated [3-11]. One of the ideas is to use the resonant tunneling effect for emission current increase from silicon tip covered multilayer film with $\delta$-doped layer. The steady state characteristics of the field electron emission structures with quantum well $(\mathrm{QW})$ have been theoreticaly and experimentaly studied in some previous works [5-11].

In this work the new preparation method of silicon tips with nanocomposite structures, namely laser modification of silicon is developed and electron field emission from nanocomposite structures in dependence on technology of forming them is investigated in detail.

\section{Experiment}

\section{A. Nanocomposite structure formation}

The laser process has been applied, one by one (single) laser pulses formed the single rather uniform conical arrays [12]. In this process a silicon substrate $(n-\mathrm{Si})$ is locally heated above its melting point by a pulse YAG : $\mathrm{Nd}^{3+}$ laser (wavelength $1.06 \mu \mathrm{m}$, pulse duration $0.2 \mathrm{~ms}$ ) and translated by X-Y $100 \mu \mathrm{m}$ resolution motor stages. Energy density of the laser processing was in the range $10-30 \mathrm{~J} / \mathrm{cm}^{2}$, that exceeds the Si melting threshold. The melting was occurred in regime of developed evaporation. As a result of the hydrodynamic blow initiated by silicon steams, the melt was forced out to the crater edges creating the rollers on the perimeter of the crater. After laser pulse influence was ceased the feed of the melt was stopped, and the rollers on the crater edges were subsided. The cone in the crater center began to grow. The melt temperature was decreased to the crystallize point and conical surface was hardened. Fig. $1 \mathrm{~b}$ presents schematic image of the crater on Si surface with cone in the crater center. Arrays with different cone distance, height, and shape could be produced by varying the conditions of laser processing. The silicon cone arrays with distance between them approximately of $\sim 50 \mu \mathrm{m}$ and height of $0-100 \mu \mathrm{m}$ with radius of the top of $\sim 1 \mu \mathrm{m}$ were prepared.

The laser ablation of $\mathrm{n}-\mathrm{Si}$ took place in air. Owing to air pressure $\left(\sim 10^{5} \mathrm{~Pa}\right)$ most of Si particles were deposited back on the target, and conical surface, too. As the pulse energy was high $(0.2 \mathrm{~J})$, there were broad distribution of particle sizes: from several nanometers to several micrometers. The lighter particles were backscattered farther from the plume axis ( as far as several millimeters) than the heavier ones. As a result the conical surface was very developed with many protrudes on it, covered with the nanocomposite film. This film consists of the nanocrystalline silicon in $\mathrm{SiO}_{\mathrm{x}}$ matrix. Photoluminescence in the visible range of spectrum was observed in this film in accordance with quantum confinement effect.

The investigation of the cone surface apexes has been carried out using scanning electron microscope (SEM). The SEM micrographs show that the cone surfaces are nanostructured and the apexes have nanometer dimen- a)

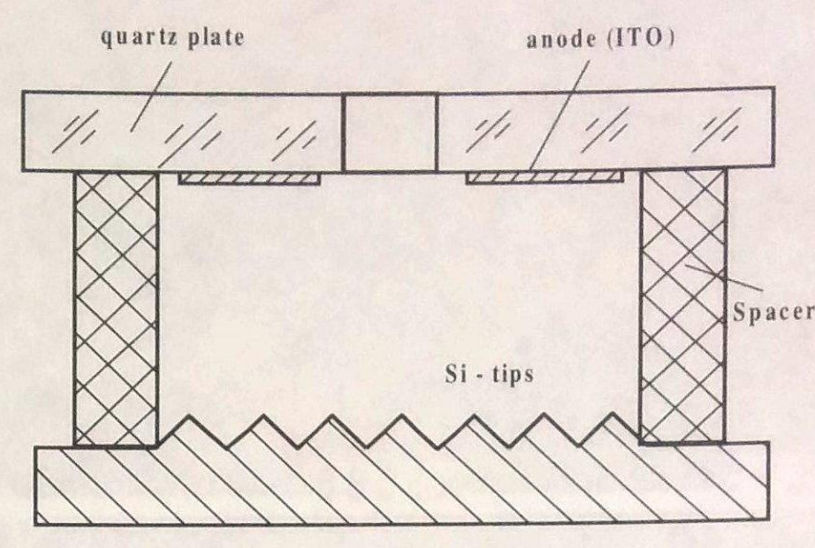

Si - wafer (cathode)

b)

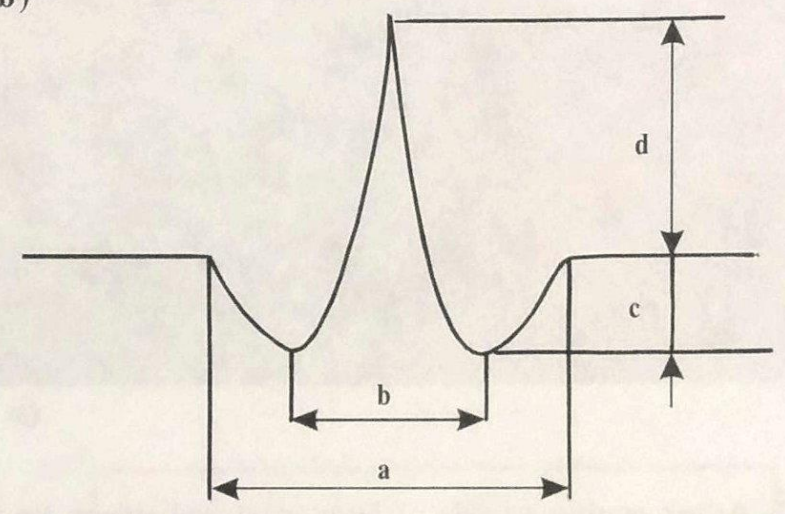

Fig. 1. Schematic images of the measurement diode structure (a) and separate laser produced cone tip (b).

sions. The deep profiling investigation of content of the silicon tips with Auger electron spectroscopy method pointed out on existence of the nanocomposite layer (nc$\mathrm{Si}_{-} \mathrm{SiO}_{\mathrm{x}}$ ) on their surface (Fig.2).

\section{B. Field emission measurements}

The measurement of the emission current from samples were performed in a vacuum system which could be pumped to the stable pressure of $10^{-6}$ Torr. The emission current was measured in the ungated cathode-anode diode structure (Fig.1a).

The emitter-anode spacing $\mathrm{L}$ was constant and equal to $20 \mu \mathrm{m}$. We fabricated a test diode construction by the sandwiching anode and cathode plates. A silicon wafer was used as the cathode and a molybdenum wire or quarts plate coated with ITO (indium-tin oxides) was used as an anode. A $20 \mu \mathrm{m}$-high fluoroplast film spacer was used to keep the two plates separated from each other. The emission current-voltage characteristics were obtained with a current sensitivity of $5 \mathrm{nA}$ over a voltage range up to $1500 \mathrm{~V}$. A $0.56 \mathrm{MW}$ resistor was placed in series with the cathode to provide short-circuit protection. 

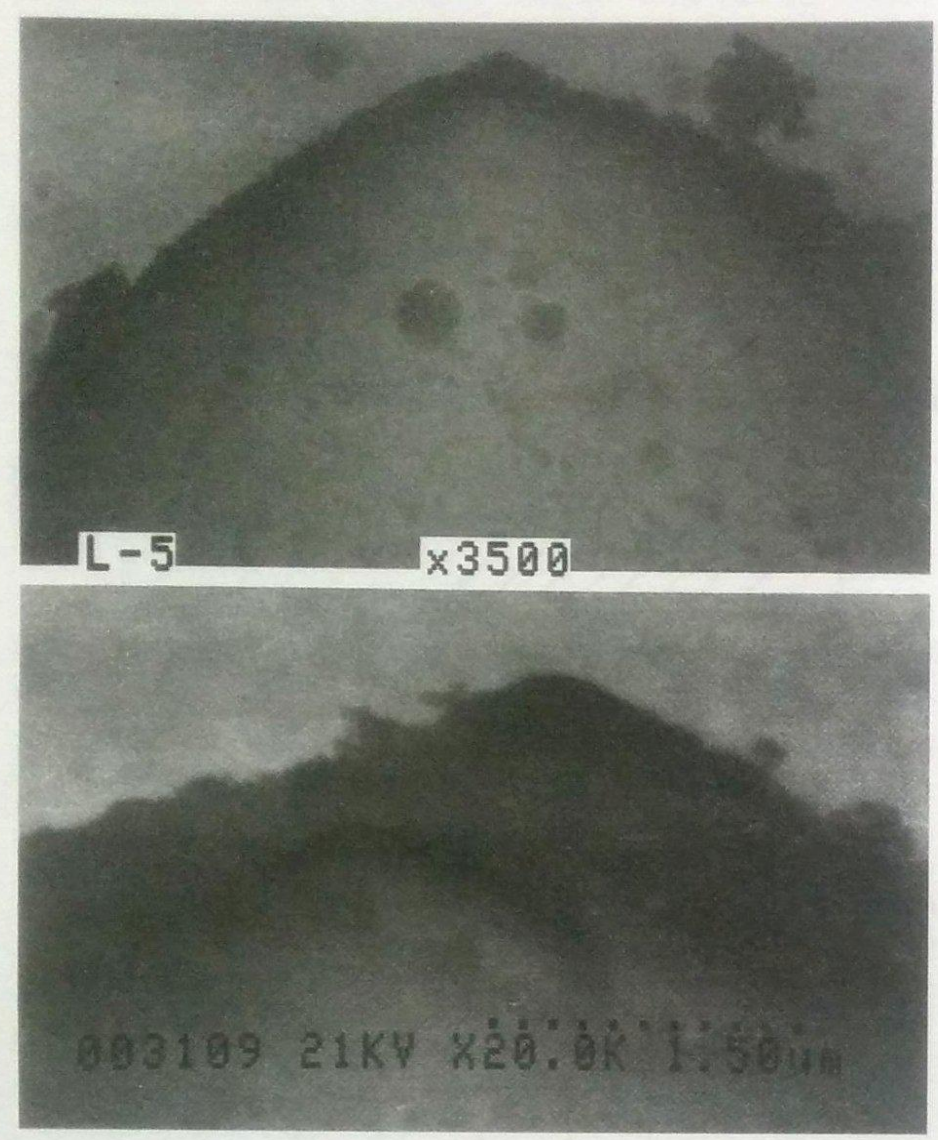

Fig. 2. Auger sputter profile of laser produced silicon tip array with nanocomposite layer.

\section{Results and discussion}

SEM micrograph of silicon-based tip array is presented in Fig. 3. It can seen that the distance between neigh boring tips is approximately $50 \mu \mathrm{m}$ and tip height $50-100 \mu \mathrm{m}$ and radius of the top is about $1 \mu \mathrm{m}$. The schematic image of the separate tip is presented in Fig. 1b. The geometrical parameters of tip $a, b, c, d$ depend on preparation conditions which influence on tip parameters strongly. This allows to produce tips with different height and aspect. In separate cases there are only craters without tips.

The strain etching causes the porous silicon layer forming on the silicon surface. As can be seen from SEM micrograph (Fig. 4) the tips covered by a porous Si layer have a high density of a very small asperites (protuberances) on the surface.

For the explanation of the features of current-voltage characteristics and comparison of them for different tip nanocomposite structures, we have determined the turnon threshold voltage $\left(V_{t h}\right)$, emitting areas (a), and local field enhancement factors (b) from the Fowler-Nordheim equation according to procedure described in [12-15]. During a and b calculation we have used $\Phi=4.15 \mathrm{eV}$ for $n$-type silicon [16]. The experimental emission parameters of the silicon-base nanocomposite structures in dependence on technology of tip forming for cases without and with strained etching are presented in Table 1. The silicon tip array with relatively high emission parameters: effective emission areas $\alpha=1.75 \times 10^{-8} \mathrm{~cm}^{2}$, local field enhancement factors $\beta=3.6 \times 10^{5} \mathrm{~cm}^{-1}$ have been obtained.

Table 1. Geometrical and field emission parameters of the laser produced tips

\begin{tabular}{|c|c|c|c|c|c|c|c|c|c|c|c|}
\hline \multicolumn{2}{|c|}{$\begin{array}{l}\text { Technological } \\
\text { parameters }\end{array}$} & \multicolumn{4}{|c|}{ Geometrical tip parameters } & \multicolumn{3}{|c|}{ Field emission parameters } & \multicolumn{3}{|c|}{$\begin{array}{l}\text { Field emission parameters } \\
\text { (strained etching) }\end{array}$} \\
\hline $\begin{array}{l}\text { Focus } \\
\text { position }\end{array}$ & $U_{p}, \mathrm{~V}$ & $\begin{array}{r}a, \\
\mu \mathrm{m}\end{array}$ & $\begin{array}{c}b, \\
\mu \mathrm{m}\end{array}$ & $\begin{array}{c}c, \\
\mu \mathrm{m}\end{array}$ & $\begin{array}{l}d, \\
\mu \mathrm{m}\end{array}$ & $\begin{array}{l}V_{t h}, \\
\text { V }\end{array}$ & $\begin{array}{c}\beta \\
\mathrm{cm}^{-1}\end{array}$ & $\alpha$, & $\begin{array}{l}V_{t h}, \\
\mathrm{~V}\end{array}$ & $\begin{array}{c}\beta \\
\mathrm{cm}^{-1}\end{array}$ & $\alpha$, \\
\hline $\begin{array}{l}\text { Focus on } \\
\text { the surface }\end{array}$ & $\begin{array}{l}450 \\
500 \\
550 \\
600 \\
\end{array}$ & $\begin{array}{l}20 \\
25 \\
35 \\
45 \\
\end{array}$ & $\begin{array}{l}10 \\
15 \\
25 \\
35\end{array}$ & $\begin{array}{c}(5) \\
(10) \\
15 \\
20 \\
\end{array}$ & $\begin{array}{l}- \\
10 \\
25 \\
45\end{array}$ & $\begin{array}{c}- \\
530 \\
280 \\
880 \\
\end{array}$ & $\begin{array}{c}- \\
3.46 \times 10^{5} \\
1.07 \times 10^{5} \\
5.8 \times 10^{4}\end{array}$ & $\begin{array}{c}- \\
5.2 \times 10^{-16} \\
1.72 \times 10^{-9} \\
3.1 \times 10^{-12}\end{array}$ & $\begin{array}{r}142 \\
1080 \\
- \\
-\end{array}$ & $\begin{array}{c}3.3 \times 10^{5} \\
2.62 \times 10^{4} \\
- \\
-\end{array}$ & $\begin{array}{c}4.52 \times 10^{-13} \\
7.82 \times 10^{-10} \\
- \\
-\end{array}$ \\
\hline $\begin{array}{l}\text { Focus } \\
\text { above the } \\
\text { surface } \\
(\sim 200 \mu \mathrm{m})\end{array}$ & $\begin{array}{l}450 \\
500 \\
550 \\
600 \\
\end{array}$ & $\begin{array}{l}25 \\
35 \\
45 \\
55 \\
\end{array}$ & $\begin{array}{l}(10) \\
15 \\
20 \\
25 \\
\end{array}$ & $\begin{array}{l}(5) \\
10 \\
10 \\
15 \\
\end{array}$ & $\begin{array}{r}- \\
- \\
10 \\
30 \\
\end{array}$ & $\begin{array}{l}480 \\
350 \\
290 \\
510\end{array}$ & $\begin{array}{l}9.4 \times 10^{4} \\
1.2 \times 10^{5} \\
3.1 \times 10^{5} \\
1.15 \times 10^{5}\end{array}$ & $\begin{array}{r}3.2 \times 10^{-12} \\
1.5 \times 10^{-11} \\
2 \times 10^{-13} \\
3.02 \times 10^{-14}\end{array}$ & $\begin{array}{l}570 \\
890 \\
670 \\
1340\end{array}$ & $\begin{array}{l}7.21 \times 10^{4} \\
3.66 \times 10^{5} \\
3.42 \times 10^{4} \\
9.71 \times 10^{3}\end{array}$ & $\begin{array}{l}5.47 \times 10^{-12} \\
9.55 \times 10^{-17} \\
1.75 \times 10^{-8} \\
5.08 \times 10^{1} \\
\end{array}$ \\
\hline $\begin{array}{l}\text { Focus } \\
\text { under the } \\
\text { surface } \\
(\sim 200 \mu \mathrm{m})\end{array}$ & $\begin{array}{l}450 \\
500 \\
550 \\
600 \\
\end{array}$ & $\begin{array}{l}35 \\
50 \\
55 \\
65 \\
\end{array}$ & $\begin{array}{l}10 \\
20 \\
40 \\
50 \\
\end{array}$ & $\begin{array}{c}(10) \\
10 \\
15 \\
20 \\
\end{array}$ & $\begin{array}{r}5 \\
10 \\
40 \\
80\end{array}$ & $\begin{array}{l}- \\
1020 \\
- \\
-\end{array}$ & $1.51 \times 10^{4}$ & $1.1 \times 10^{-3}$ & $\begin{array}{l}330 \\
660 \\
390 \\
580\end{array}$ & $\begin{array}{c}7.2 \times 10^{4} \\
- \\
- \\
-\end{array}$ & $\begin{array}{l}3.71 \times 10^{-8} \\
8.84 \times 10^{-10} \\
7.32 \times 10^{-13} \\
3.74 \times 210^{-9} \\
\end{array}$ \\
\hline
\end{tabular}




\section{A.A. Evtukh et al.: Field emission of electrons from laser produced silicon tip arrays}
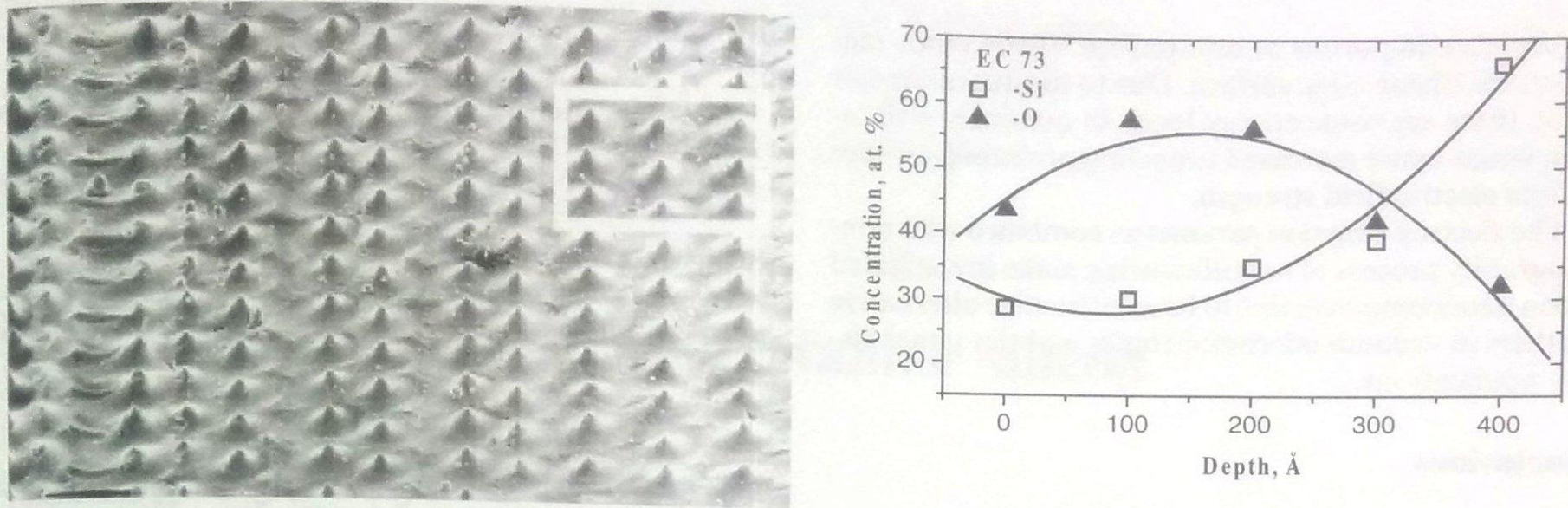

Fig. 4. SEM micrograph of strain etched silicon surface of the laser produced silicon tip.

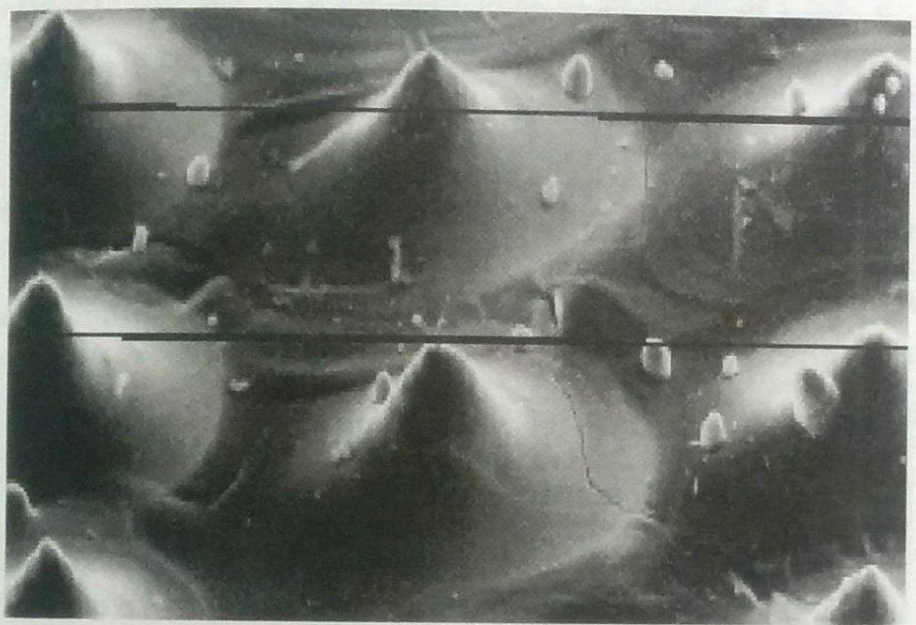

The resonant tunneling phenomenon have been discovered on some samples with nanocomposite structures. As a rule, two or one resonant peaks have been observed (Fig.5). The current voltage curves have asymmetry in current maximum region which is determined by peculiarities of electron transport through resonant tunneling structures. These structures consist of $\mathrm{Si}$ quantum size
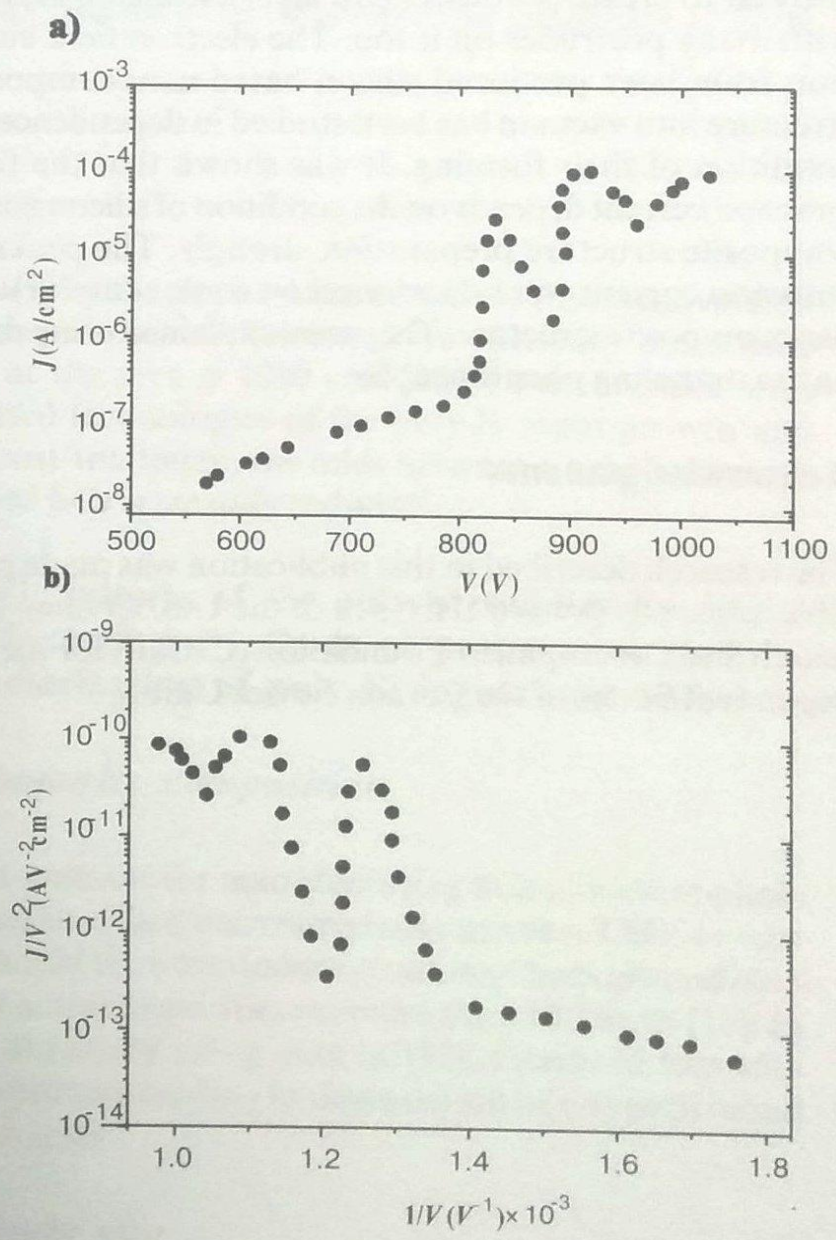

Fig. 5. Field emission current-voltage characteristic (a) and the corresponding Fowler-Nordheim plot (b) of the laser produced Si-based nanocomposite structure with resonance tunneling.

Fig. 3. SEM micrograph of the laser produced silicon tip array. 


\section{A.A. Evtukh et al.: Field emission of electrons from laser produced silicon tip arrays}

nanocrystals in porous or non-porous silicon oxide matrix on the silicon cone surface. Due to the quantum-size effect, there are some energy levels in quantum well region, which cause increased tunneling probability under definite electric field strength.

The electron emission parameters combined with nonlithography process of manufacturing make investigated silicon nanocomposite tips to be an attractive alternative to others in vacuum microelectronics and flat panel display applications.

\section{Conclusions}

The electron field emission from silicon-based nanocomposite structures have been investigated and the new method of the tip and tip array creation have been developed. This method based on laser modification of silicon. The laser direct-recording process has been applied, one by one (single) laser pulses formed the single rather uniform conical tips. Arrays with different tip distance, height and shape of tips have been produced by varying the condition of laser processing. As a result of intensive laser pulse influence, the silicon surface was very developed with many nanometer size protrudes on it covered with nanocomposite films $\left(\mathrm{nc}-\mathrm{Si}-\mathrm{SiO}_{\mathrm{x}}\right.$ ). The stain etching allowed to create porous silicon layer on silicon surface with many protrudes on it too. The electron field emission from laser produced silicon based nanocomposite structure into vacuum has been studied in dependence on condition of their forming. It was shown that the field emission current depends on the condition of silicon nanocomposite structure preparation strongly. The peaks of emission current were discovered on some samples with nanocomposite structure. They were explained using resonance tunneling phenomenon.

\section{Acknowledgements}

The research described in this publication was made possible in part by Award UE1-316 of the U.S. Civilian Research and Development Foundation (CRDF) for the Independent States of the Former Soviet Union.

\section{References}

1. K. Derbyshire, Beyond AMLCDs: Field emission displays // J.Solid State Technol., November, pp. 55-58 (1994).

2. G. Yang, K.K. Shin, R.B. Marcus, Electron field emission through a very thin oxide layer // IEEE Trans. Electron. Dev., 38(10),pp. 2373-2375(1991)

3. K.C. Park, J.N. Moon, S. J. Chung, J.H. Jung, B.K. Ju, M.H Oki, W. I. Milne, M.K. Han, Jang // Proccedings of the $9^{\text {th }}$ IVMC'96, pp. 298-302. (1996)

4. V.G. Litovchenko, A.A. Evtukh, R.I. Marchenko, N.I. Klyui, V. A. Semenovich, Enhancement of field emission from cathodes with superthin diamond-like carbon film // Appl. Surf. Sci., 111, pp.213-215 (1997).

5. L.S. Pan T.E. Felter, D.A.A. Oklberg, W.L. Hsu, C.A. Rox, R. Cao, and G. Vergara // J. Appl. Phys., .82(5), pp.26242627 (1997).

6. A.A. Evtukh, V.G. Litovchenko, R.I. Marchenko, S.Yu. Kudzinovski, Layered structures with delta-doped layers for enhancement of field emission // J. Vac. Sci. Tecnol., B15(2), 1-4 (1997).

7. P.R. Wilshaw, E.C. Boswell, Emission characteristics and morphology of wet etched cathodes in p-type silicon // J. Vac. Sci. Technol., B12(2), 662-665 (1994).

8. A.A. Evtukh, V.G. Litovchenko, R.I. Marchenko, N.I. Klyui, V.A. Semenovich, C. Nelep, Parameters of the tip arrays covered by low work function layers // J.Vac. Sci. Technol., B14(3), 2130-2134 (1996).

9. V.G. Litovchenko, Yu.V. Krychenko, Field emission from structures with quantum wells //J. Vac. Sci. Technol., B11(2), 2130-2132 (1993).

10. V.G. Litovchenko, Yu.V. Krychenko, The dynamic characteristics of the field emission from the structures with quantum wells // J. de Physique IV, 6, C5-141-143 (1996).

11. V.G. Litovchenko, A.A. Evtukh, Yu.M. Litvin, N.M. Goncharuk, V.E. Chayka, Observation the resonant field emission in the silicon tips arrays // J.Vac. Sci. Technol., B17, 655-658 (1999).

12. A.A. Evtukh, E.B. Kaganovich, V.G. Litovchenko, R.I. Marchenko, E.G. Manoilov, S.V. Svechnikov, Fabrication and characterization of laser produced silicon field emission arrays // Proccedings of the $10^{\text {th }}$ IVMC'97, p.200-204. (1997),

13. W. Branston and D. Stephany, Field emission from metalcoated silicon tips // IEEE Trans. Electron. Devices ED-38, 2329-2332 (1991)

14. I. Brodie, C.A. Spindt, Vacuum microelectronics // Adv. In Electronics and Electron Phys. 83, 1-8 (1996).

15. V.G. Litovchenko, A.A Evtukh, R.I. Marchenko, N.I. Klyui, and V.A. Semenovich, The enhanced field emission from microtips covered by ultrathin layers // J. Micromech. Microeng. 7, 1-8 (1997).

16. S.M. Sze, Physics of Semiconductor Devices, (Wiley Interscience Publication, John Wiley \& Sons, pp. 364-368, New York, (1981). 